\title{
Practice-Led Fine Arts Doctorate: The Controversy on New Knowledge
}

\author{
Rongwei Zhang ${ }^{1, *}$ \\ ${ }^{1}$ The Glasgow School of Art, 167 Renfrew Street, Glasgow G3 6RQ, UK \\ "Corresponding author. Email: zhangrongweigsa@126.com

\begin{abstract}
Although the current situations of Practice-led Fine Arts Doctorate courses in different countries are extremely different, it seems to be a trend that this course is becoming a kind of regularity in universities. However, debates on how this mode of research creates new knowledge, and whether this new mode of research creates new knowledge are still fierce. Among these debates, theories of tacit knowledge of encounter are significant. While defending the academic legitimacy of Practice-led Fine Arts Doctorate, they also provide new perspectives and possibilities on the connections between visual art and other subjects.
\end{abstract}

\section{Keywords: Practice-led Fine Arts Doctorate, tacit knowledge, encounter and recognition}

\section{INTRODUCTION}

Practice-led Fine Arts Doctorate is an academic research mode that is in the process of establishing rules. This model believes that artistic practice centered on creation and viewing can also be a research methodology that generates new knowledge. At present, some countries, represented by the United Kingdom and Australia, have a positive attitude towards this new research model and have widely set up this course in Chinese universities. Some scholars in North America are skeptical of this research model. This article starts with an introduction to the development status of Practice-led Fine Arts Doctorate in various countries, and focuses on the current controversies that this research model is suffering from, such as whether it can generate new knowledge and what is the difference between it and scientific research. In addition to supporting the legitimacy of the Practice-led Fine Arts Doctorate course as an academic research model, these discussions also point out the potential of this research model in promoting individual "tacit knowledge", and provide a reference for how to design and implement this course in universities.

\section{THE DEVELOPMENT STATUS OF PraCtiCE-LED Fine ARTS DOCTORATE IN VARIOUS COUNTRIES}

Since its development, the Doctor of Fine Arts is no longer a purely theoretical research course. At present, European countries generally offer the Practice-led Fine Arts Doctorate with artistic practice as a research methodology in universities. For example, under the British model, doctoral studies in fine arts are divided into purely theoretical and practice-led types. The purely theoretical doctor of fine arts research mainly studies art history, aesthetics and art theory and so on. In most cases, researchers who participate in purely theoretical fine arts research do not need to personally conduct artistic practices such as painting or sculpture during the research process. The entire research process is also roughly in line with the traditional research process of "1. Determining the scope of the research; 2. Studying related documents; 3. Selecting the analysis angle; 4. Making original contributions to knowledge" (Macleod and Holdridge, 2006: xiii). This type of fine arts doctoral course widely exists in universities in various countries, and the opposite is the emerging practice-led fine arts doctoral courses. Both are closely related to visual art. The biggest difference is that the primary identity of visual art in purely theoretical art studies is the research object, while its identity in practice-led art studies is the research method. In other words, the Practice-led Fine Arts Doctorate is a research model that generates new knowledge through artistic practice. However, as the British educator Sir Christopher Frayling pointed out that, around the question of "whether artistic practice can produce communicative knowledge", the academic legitimacy of the Practice-led Fine Arts Doctorate is undergoing fierce controversy, and its development status in different countries is also very different (Macleod and Holdridge, 2006: xiii).

Statistics conducted by Professor James Elkins of the School of the Art Institute of Chicago in 2014 showed that at that time, only the United Kingdom, Australia and Japan relatively generally set up Practiceled Fine Arts Doctorate course in universities. Among them, the United Kingdom has set up this course in 41 
universities, and Australia and Japan have set up Practice-led Fine Arts Doctorate course in 22 and 26 universities respectively. In contrast to these countries, only 32 universities in the European Union (EU) (along with the EU candidate countries) except the United Kingdom have set up Practice-led Fine Arts Doctorate. This number is only 5 in Canada and 6 in the United States (Elkins, 2014: 22-32). More noteworthy than the numbers is the different attitudes of these countries towards the Practice-led Fine Arts Doctorate course. The mainstream academic circles in the United Kingdom and Australia are basically positive towards the proposition of "making original contributions to knowledge through artistic practice". Scholars from these two countries such as Sir Christopher Frayling, Professor Simon O'Sullivan of Goldsmiths, University of London, and Professor Barbara Bolt of University of Melbourne have published monographs discussing how artistic practice makes original contributions to knowledge. However, inconsistent with these opinions, Professor Elkins pointed out when discussing the development status of the Practice-led Fine Arts Doctorate in the United States that the Practice-led Fine Arts Doctorate course is often regarded as an extended version of the Master of Fine Arts in the United States. Students continue to stay in school for three or four years after graduating from a master's degree, but they have no clear purpose. (Elkins, 2014: xii)

The embarrassing situation of the Practice-led Fine Arts Doctorate in the United States is not incomprehensible. After all, the standard for completing a Doctorate is that students have successfully made original contributions to knowledge, while the pursuit of artistic practice such as painting and sculpture is personal originality and non-replicability. From the perspective of the creator, artistic practice is a practice that has no commonality or even deliberately rejects commonality. Similarly, different audiences are unlikely to have absolutely the same viewing experience when viewing a work of art. In other words, no matter from the perspective of the creator or the audience, art is not based on commonality. And without the support of commonality, artistic practice is incommunicable to a large extent. Therefore, whether what is produced by artistic practice can be regarded as knowledge is itself a question that can be discussed. It is in this sense that Professor Elkins questioned in the book "Thinking Through Art: Reflections on Art as Research", why should people look at visual art from the perspective of science? What new knowledge can artists such as Picasso's work produce? After throwing out these two difficult questions, Professor Elkins pointed out quite sharply that universities in the United Kingdom, Australia, Ireland and other countries offer Practice-led Fine Arts Doctorate course purely for economic purposes. Because in the systems of these countries, the more courses universities offer, the more funds they can receive from the government to hire more faculty members and expand the scale of their schools. (Macleod and Holdridge, 2006: 241)

\section{TYPES AND DIVISION OF KNOWLEDGE}

Although difficult to answer, these two questions raised by Elkins are not incontrovertible. His question "why should people look at visual art from the perspective of science?" implies that he seems to think that only formulas such as $\mathrm{S}=\mathrm{v} 0 \mathrm{t}+1 / 2$.at^ 2 that can be determined and transmitted through words, symbols and language can be regarded as knowledge. Based on this premise, the works of artists such as Picasso really can't generate new knowledge. Although the two sides hold different views on the issue of whether artistic practice should be regarded as academic research, British scholars who support Practice-led Fine Arts Doctorate may not necessarily object to the view of Elkins that "art can't produce scientifically definite and propagable knowledge". For example, in his article "The Aesthetics of Affect: Thinking Art Beyond Representation", British artist Simon O'Sullivan clearly pointed out that "the primary purpose of art is not to 'reasoning', but to explore the various possibilities of existence and change. Art is not directly related to knowledge, it is more related to 'experience' and exists to 'expand the range of human experience' (O'Sullivan, 2001: 30)". It is not difficult to see that the consensus of both parties is that art can't produce the knowledge of scientific type. The British academic circles' integration of artistic practice into academic research is based on their understanding and definition of knowledge and is different from Elkins.

When talking about the issue of "new knowledge generated by artistic practice", scholars in the United Kingdom and continental Europe often cite the tacit knowledge proposed by the British Hungarian scholar Michael Polanyi in his book "Personal Knowledge" in 1958 to support the argument that "artistic practice can generate new knowledge". In "Personal Knowledge", Polanyi made a clear distinction between tacit knowledge and explicit knowledge. In Polanyi's discussion, explicit knowledge is the knowledge that can be fully expressed by humans in a certain code system (such as various formulas in mathematics, physics and chemistry). In contrast, tacit knowledge refers to the kind of knowledge that people know but can't describe (Polanyi, 1985). For example, the contemporary Dutch philosopher Henk Borgdorff identified three main types of knowledge in his article "The Production of Knowledge in Artistic Research". One is the propositional knowledge, which is the core of traditional epistemology (That is, knowledge of facts about the earth. For example, the chemical molecular structure of water is two hydrogen atoms plus one oxygen atom); the second is knowledge as skill, such as a new computer software operation method; and the 
third type is this kind of tacit knowledge that is difficult to describe. In subsequent analysis, Borgdorff stated that these three types of knowledge are difficult to be completely separated. Different models of academic research also have different emphasis on the types of knowledge generated, while the artistic practice produces mainly tacit knowledge. (Biggs and Karlsson, 2011: 55) Borgdorff's division of knowledge types makes Elkins's "artistic practice unable to produce knowledge" invalid to a certain extent. However, he didn't clearly point out what kind of tacit knowledge can be produced by artistic practice.

Fortunately, a complement to Borgdorff in the statement of Mark Johnson, a philosophy professor at the University of Oregon, can be found. Johnson believes that the practice of art is regarded as academic research that generates knowledge because "the practice of a good artist is an uninterrupted exploration of the nature of her/his material. The artist is trying to discover how to manipulate these materials to create a certain effect, and how to expand the potential of these materials. (Biggs and Karlsson, 2011: 144)" This echoes the claim of O'Sullivan that "art is not directly related to knowledge, it is more related to 'experience' and exists to 'expand the range of human experience' (O'Sullivan, 2001: 30)". After all, achieving a new effect in artistic creation itself expands the scope of human experience. However, if people believe that only behaviors that produce scientific knowledge or propositional knowledge can be regarded as academic research, due to its lack of certainty and communicability, this kind of artistic practice that can generate new effects can't be counted as academic research.

For example, even if the same batch of paint produced by the same manufacturer is used, it is unlikely that different painters will paint absolutely the same works. It supposes a certain painter pursues creating a gentle and mild visual effect on the painting. By repeatedly manipulating the paint, she/he achieves the desired result. In other words, after practice again and again, the painter masters a method to achieve the kind of visual effect he expects. In other words, through painting, the painter has mastered a kind of tacit knowledge to create a certain visual effect. However, since this knowledge is mastered through repeated practice of a series of uninterrupted movements such as toning, smearing, wiping and scratching, it is indeed unlikely to be spread through speeches or words. It supposes the painter wants to teach someone the skill of creating gentle and mild visual effects, then she/he must accurately quantify and communicate the strength and amplitude of his/her own toning, wielding the pen, etc. to her/his students, and this is obviously not feasible. Therefore, those who support Elkins' view would think that although the painter has cultivated a kind of tacit knowledge, since this knowledge can't be effectively determined and passed on to others, the practice of this painter can't be regarded as academic research.

\section{THE "ENCOUNTER-STYLE" DISSEMINATION OF TACIT KNOWLEDGE}

However, artistic practice is not a closed process in which the creator alone appreciates himself. From the perspective of the audience, watching a work of art is itself a perception. From the perspective of the creator, creating a work is an expression of one's own thoughts and emotions. Therefore, the transmission and perception of information and emotions occupy a central position in the complete process of "from creation to viewing" in artistic practice. It is just that compared with the transmission of scientific knowledge, even at the level of information transmission, artistic practice can't transmit the information accurately and without emotion as the chemistry teacher transmits "The chemical formula of water is H2O". The most typical example is the question "What kind of information does Vinci want to convey through the 'Mona Lisa'", which has been discussed and debated for centuries, but it is still inconclusive. What's more, the artist's creation and the audience's viewing are affected by subjective emotions, and people's emotions are always changing. Therefore, even for the same audience, the experience of watching the same artwork twice may be completely different.

The personalization and uncertainty in the dissemination of information and emotions in artistic practice makes some scholars not think it can become academic research. However, the "encounter" theory proposed by O'Sullivan in his book "Art Encounters Deleuze and Guattari: Thought Beyond Representation" seems to provide support for the legitimacy of artistic practice as academic research. O'Sullivan pointed out in the book that when touching things, all human perceptions can be divided into two types: "encounter" and "recognition". According to analysis of O'Sullivan, what can provide an "encounter-type experience" is probably an event or object like this: after a person has experienced the event or object, her/his habitual thinking or viewpoint will be stimulated and destroyed, prompting her/him to reflect on the thoughts, opinions or environment she/he is accustomed to, and then generates new ideas, understandings or opinions. In other words, "encounter-type experience" is an experience that destroys first and then establishes for experiencer. In contrast, "recognition-type experience" is something that a person has experienced that conforms to his habitual thinking or viewpoint. After the experience, the experiencer will have thoughts such as "I can completely explain this event" or "Sure enough, as I thought". (O'Sullivan, 2006: 1) O'Sullivan believes that "encounter-type experience" is the attribute that a work of art should have. In other words, 
an excellent work of art must stimulate the audience's world outlook, make the audience doubt their own habitual thinking, and then create new ideas, opinions or beliefs under the stimulation of the work. In this way, creativity can be extended from the artist to the audience, and the real end of the work has become a new idea and new understanding generated by the audience after they doubt it.

It is not difficult to see that the point of view of O'Sullivan is that although creators can't guarantee that their attitudes, thoughts or emotions can be accurately transmitted to the audience through creation and being viewed, the audience can obtain personal new ideas, understandings and concepts through the "encountertype" experience during the viewing process. As discussed in the previous article, Mark Johnson's theory believes that the new knowledge generated by artistic practice is the method that the creator masters to produce new visual effects through continuous exploration of the materials used. This argument supports the view that "the practice of an artist can be a research that generates new knowledge", although the knowledge generated by this research is personal and indescribable tacit knowledge. And the "encounter" theory of O'Sullivan provides support for another part of artistic practice, namely, why the audience's viewing can be a research method for generating new knowledge. So far, the artistic practice centered on "creation" and "viewing" has been basically cleared as a logic of academic research that generates new knowledge.

Of course, this logic is not perfect. The artist's creation is not always innovative, and empty and repetitive works are common. Similarly, the audience doesn't always experience something when watching a work of art, and it is common to see things without a ripple inside. Therefore, only when certain conditions are met can artistic practice produce personal tacit knowledge. For example, the artist is really exploring the relationship between materials, effects and ideas rather than just repeating the techniques he has already mastered, and the audience just happens to be moved by the works. But this is not a characteristic of artistic practice. Even the dissemination of scientific knowledge needs to meet certain conditions. For example, only when someone has preliminary chemical knowledge, the knowledge that "the chemical formula of water is H2O" can be understood, otherwise $\mathrm{H} 2 \mathrm{O}$ is just an empty symbol to her/him. The dissemination of scientific knowledge or propositional knowledge is copy-type. Once the researcher draws a conclusion that has been proven to be correct, the conclusion will be copied and propagated integrally under certain conditions. However, the dissemination of tacit knowledge generated by artistic practice is evolutionary. The artist's practice may only produce tacit knowledge that is effective for her/himself.
Through the viewing of the work, the audience may obtain tacit knowledge that is different from the artist. From the artist's practice to the audience's observation, tacit knowledge continues to evolve among different individuals, and this evolution of tacit knowledge exacerbates the differences between individuals. The core argument put forward by the French poststructuralism philosopher Gilles Deleuze in his 1968 book "Difference and Repetition" is that the first principle of things is difference rather than identity, because the identity of things is a temporary state, and the differences between things provide the possibility for the next evolution of each identity. Therefore, the inter-individual differences brought about by artistic practice provide richer possibilities for the next development and evolution of artists and audiences.

\section{CONCLUSION}

As a mode of academic research, artistic practice is still in the stage of establishing rules. Although it is not very mature, its potential and enlightenment in promoting individual development and evolution can't be ignored. The proposition of "using scientific knowledge or propositional knowledge as the sole criterion for academic research" itself may be a constraint on academic research. Just as some European first-line art colleges, such as Central Saint Martins College of Arts and Design in London, have set up the master courses of art and science (MA Art and Science), which aims to study the cross-border relationship among artists, scientists, curators, etc.; in the contemporary context, "cross-border connection between disciplines and concepts" is a trend that can't be ignored and is full of potential. Therefore, the tacit knowledge that can be produced by artistic practice and the traditional scientific academic research is not completely without space for combination, and how to set up a Practice-led Fine Arts Doctorate in China in accordance with its national conditions has become a problem worthy of discussion.

\section{References}

[1] Macleod, K. and Holdridge, L. ed.. Thinking Through Art: Reflections on Art as Research [M]. Routledge. 2006.

[2] Frayling, C. Research in Art and Design [A]. Royal College of Art Research Papers. 1993.

[3] Elkins, J. ed.. Artists with Doctorates: On the New Doctoral Degree in Studio Art [M]. New Academia Publishing. 2014.

[4] O'Sullivan, S. The Aesthetics of Affect: Thinking Art Beyond Representation [A]. Angelaki Journal of the Theoretical Humantities, 2001: 25-35.

[5] O'Sullivan, S. Art Encounters Deleuze and Guattari: Thoughts Beyond Representation [M]. Palgrave Macmilan. 2006.

[6] Bolt, B. Art Beyond Representation: The Performative Power of the Image [M]. I.B. Tauris. 2001.

[7] Polanyi, M. Personal Knowledge: Toward a Post-Critical Philosophy [M]. Routledge. 1958. 
[8] Borgdoff, H. The Production of Knowledge in Artistic Research [A]. The Routledge Companion to Research in the Arts, Routledge. 2011

[9] Johnson, M. Embodied Knowing Through Art [A]. The Routledge Companion to Research in the Arts, Routledge. 2011.

[10] Deleuze, G. Difference and Repetition [M]. Columbia University Press. 1994. 